\title{
Hidradenitis suppurativa: from pathogenesis to diagnosis and treatment
}

\author{
Maddalena Napolitano' \\ Matteo Megna ${ }^{2}$ \\ Elena A Timoshchuk ${ }^{3}$ \\ Cataldo Patruno ${ }^{2}$ \\ Nicola Balato 2 \\ Gabriella Fabbrocini ${ }^{2}$ \\ Giuseppe Monfrecola ${ }^{2}$ \\ 'Dipartimento di Medicina e Scienze \\ della Salute "Vincenzo Tiberio", \\ Università degli Studi del Molise, \\ Campobasso, ${ }^{2}$ Section of Dermatology, \\ Department of Clinical Medicine and \\ Surgery, University of Naples Federico \\ II, Naples, Italy; ${ }^{3}$ Department of \\ Dermatovenereology, Saint Petersburg \\ State Pediatric Medical University, \\ Saint Petersburg, Russia
}

Correspondence: Maddalena Napolitano Dipartimento di Medicina e Scienze della Salute "Vincenzo Tiberio", Università degli Studi del Molise, C/da Tappino, 86100 Campobasso, Italy

Email maddalena.napolitano@unimol.it
This article was published in the following Dove Press journal:

Clinical, Cosmetic and Investigational Dermatology

19 April 2017

Number of times this article has been viewed

\begin{abstract}
Hidradenitis suppurativa (HS) is a chronic inflammatory skin disease primarily affecting apocrine gland-rich areas of the body and presenting with painful nodules, abscesses, sinus tracts, and scarring. HS is a multifactorial disease in which genetic and environmental factors play a key role. The primary defect in HS pathophysiology involves follicular occlusion of the folliculopilosebaceous unit, followed by follicular rupture, and immune responses (perifollicular lympho-histiocytic inflammation), finally leading to the development of clinical HS lesions. HS has a destructive impact on the patient's quality of life, being a very challenging disease. Available treatments are limited, mostly off-label and with high variability in the reported efficacy. Fortunately, a monoclonal antibody against tumor necrosis factor alpha has been recently approved for treatment of moderate to severe HS, offering patients a promising new option. This review focuses on the main features of HS, including epidemiology, clinical aspects, pathogenesis, severity classifications, comorbidities, and currently available treatments.
\end{abstract}

Keywords: hidradenitis suppurativa, pathogenesis, diagnosis, treatment

\section{Introduction}

Hidradenitis suppurativa (HS) is a chronic, inflammatory, debilitating skin disease characterized by recurrent, painful, nodules and abscesses that rupture, leading to the formation of sinus tracts and scarring. ${ }^{1}$ Lesions usually affect apocrine gland-bearing anatomical areas of the body. HS typically occurs after puberty, with the average age of onset in the second or third decades of life and with a female predominance. ${ }^{2}$ Onset after menopause is rare, but isolated case reports have described HS development in prepubescent subjects experiencing premature adrenarche. ${ }^{3}$ Due to its chronic nature and frequently occurring relapses, HS has a great impact on the patient's quality of life, deeply affecting social, working, and psychological aspects. ${ }^{3}$ The exact prevalence of HS remains unknown: in Europe, several studies have estimated a prevalence of $1 \%$ in the general population ${ }^{4,5}$ and of $4 \%$ in young adult women, ${ }^{6}$ whereas epidemiological data from American surveys reported a prevalence between $0.05 \%$ and $0.20 \% .{ }^{7,8} \mathrm{As}$ there is no biological or pathological test to facilitate diagnosis, HS is defined only by its clinical features and its chronicity.

Early diagnosis is very important for HS patients in order to ensure the best possible course of this stigmatizing and painful disease and to reduce the number of working days lost through sickness and HS-related healthcare issues. However, HS diagnosis generally occurs after an average 7-year delay. ${ }^{9}$ Due to the peculiar clinical aspects of HS, non-dermatologists such as primary care physicians and surgeons are often the 
first providers to see HS patients and may have difficulty identifying the condition, even if the clinical presentation is typical and a reliable diagnosis can be made based on simple questions. ${ }^{10}$

This review highlights the main features of HS in order to increase the awareness of this disease, avoid delay in diagnosis, and ensure prompt disease management.

\section{Etiology and pathogenesis}

The exact etiology of HS is still unproven. In the last few years, numerous studies hypothesized that the disease is triggered by genetic and environmental factors (Figure 1). ${ }^{1,7,11-13}$

Cigarette smoking, obesity, and overweight are eminent environmental risk/trigger factors in HS development. ${ }^{5}$ At the same time, the importance of genetic factors is highlighted by studies showing that $30 \%-40 \%$ of HS patients reported a family history of HS. ${ }^{5,14,15}$ Moreover, familial forms of HS following an autosomal dominant pattern of inheritance with $100 \%$ penetrance have been described in different populations, being linked to mutations in subunits of the gammasecretase proteins (up to $5 \%$ of HS cases). ${ }^{16-18}$

The primary defect in HS pathophysiology involves occlusion and subsequent inflammation of the hair follicle; these conditions, together with both innate and adaptive immune dysregulation, are necessary to initiate the development of clinical HS. ${ }^{19}$ Bacterial infection and colonization are considered a secondary pathogenic factor that can worsen HS. Follicular occlusion leads to dilatation followed by rupture, resulting in the follicular contents, including keratin and bacteria, spilling into the surrounding dermis and inducing a vigorous chemotactic response from neutrophils and lymphocytes. The inflammatory cellular infiltrate causes abscess formation, leading to the destruction of the pilosebaceous unit and eventually of other adjacent adnexal structures. ${ }^{1,11,20-23}$ Other factors that may contribute to HS include altered expression of antimicrobial peptides' abnormal secretion of apocrine glands, abnormal invaginations of the epidermis leading to sinus tract formation, and deficient numbers of sebaceous glands. ${ }^{24-30}$

The basis for follicular occlusion in HS is yet to be fully defined. Melnik and Plewig recently proposed the concept of HS as an auto-inflammatory disease characterized by dysregulation of the gamma-secretase/Notch pathway. ${ }^{31,32}$ Appropriate Notch signaling is of pivotal importance for maintaining the inner and outer root sheath of the hair follicle and skin appendages. Deficiency in the Notch signaling pathway results in conversion of hair follicles to keratin-enriched epidermal cysts, compromises apocrine gland homoeostasis, and leads to the stimulation of toll-like receptor (TLR)mediated innate immunity, supporting and maintaining

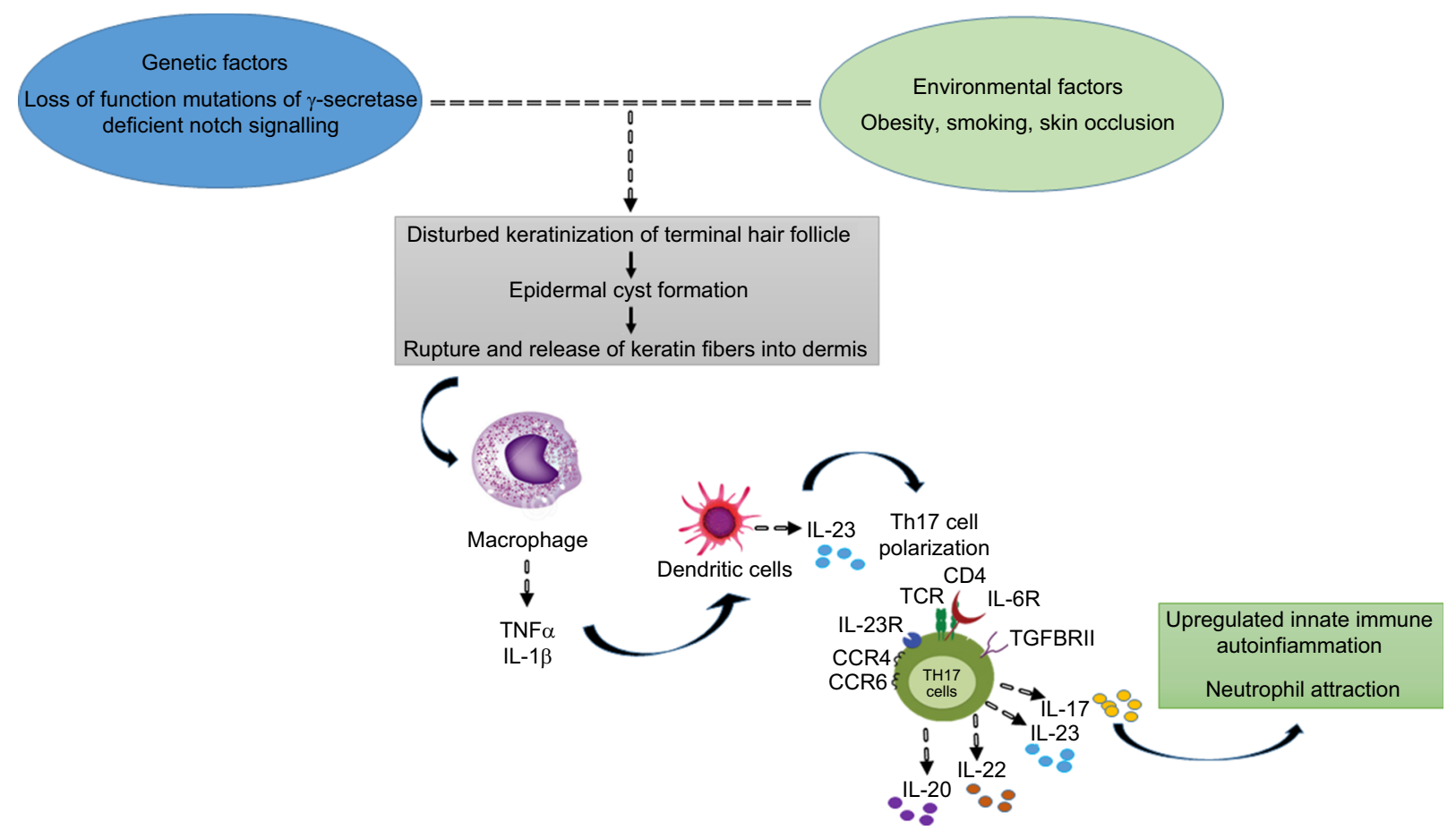

Figure I Hidradenitis suppurativa pathophysiology: a schematic overview. Abbreviations: TNF- $\alpha$, tumor necrosis factor- $\alpha$; IL, interleukin. 
chronic inflammation. ${ }^{33,34}$ In support of this hypothesis, elevated levels of several pro-inflammatory cytokines, most notably tumor necrosis factor (TNF)- $\alpha$, interleukin (IL)-1 $\beta$, and IL-17, have been observed in HS lesions. ${ }^{35}$ Altered TLRs signaling on macrophages and dendritic cells (DCs), the most abundant cells in HS lesions, produces increased amounts of these cytokines, leading to activation of DCs, which secrete IL-23 promoting Th17 cell polarization (IL-17-producing $\mathrm{T}$ helper cells were found to infiltrate the dermis in chronic HS lesions). ${ }^{35-40}$ In particular, one of the major actors in HS pathogenesis is TNF- $\alpha$, whose overexpression has been observed in lesional and perilesional skin of HS, together with a positive correlation with disease severity. ${ }^{41}$ Hence, it is clear that HS is a follicular disease showing some defect in keratin clearance, with resultant follicular occlusion, where defective innate cellular immunity plays an important role. ${ }^{42}$

Although HS is not primarily an infectious disease, the role of bacteria seems to be very important in HS pathophysiology. Follicular hyperkeratinization and occlusion result in the rupture of pilosebaceous units, releasing bacteria within the dermis and triggering a local inflammatory response and thereby sustaining chronic inflammation. In addition, colonies of specialized bacteria that are difficult to eradicate form bacterial biofilms that bind irreversibly to sinus tract epithelium and hair follicles, further sustaining chronic inflammation. ${ }^{43,44}$ A microbiological study of 102 HS lesions from 82 patients showed Staphylococcus lugdunensis to be the most prevalent species, found as a unique or predominant isolate in $58 \%$ of HS nodules and abscesses. ${ }^{26}$ Other common species dominating HS lesions included polymicrobial anaerobic microflora consisting of strict anaerobes, milleri group streptococci, and actinomycetes (found in $24 \%$ of abscesses or nodules and in $87 \%$ of chronic suppurating lesions). ${ }^{26}$

\section{Clinical aspects}

In general, HS is localized in the apocrine gland-bearing areas of the body such as axillae, inguinal and anogenital regions, perineum, and inframammary area of female patients (although aberrant lesions may occur in the waist, abdomen, specially periumbilical region, and thorax). ${ }^{1}$ The sites affected by HS correspond not only to the location of apocrine glands but also to the location of terminal hair follicles dependent on low androgen concentrations. ${ }^{45}$ HS is initially characterized by the presence of tender subcutaneous nodules (commonly indicated as "boils" or "pimples") (Figures 2 and 3). Up to $50 \%$ of patients report a burning or stinging sensation, pain, pruritus, warmth, and/or hyperhidrosis, 12-48 hours before

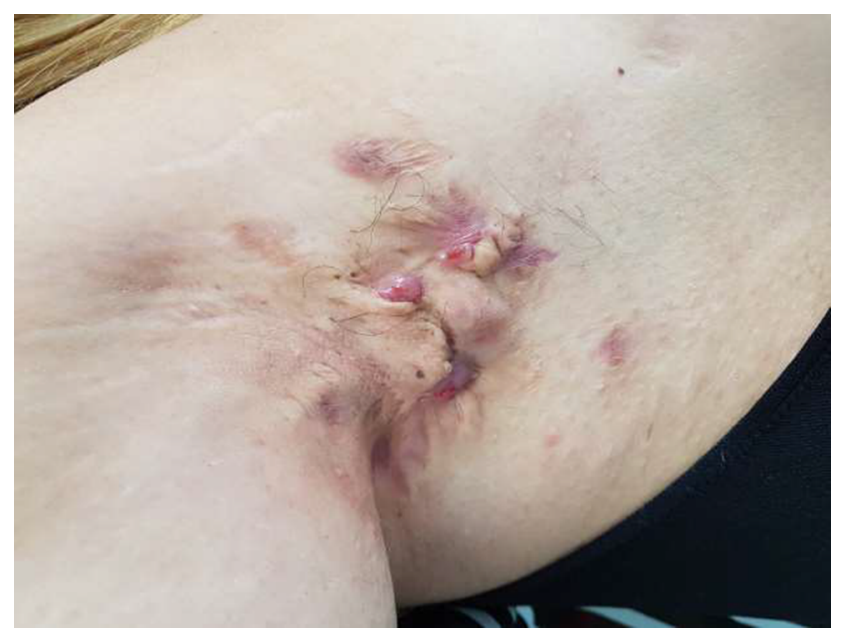

Figure 2 Hidradenitis suppurativa: clinical aspects.

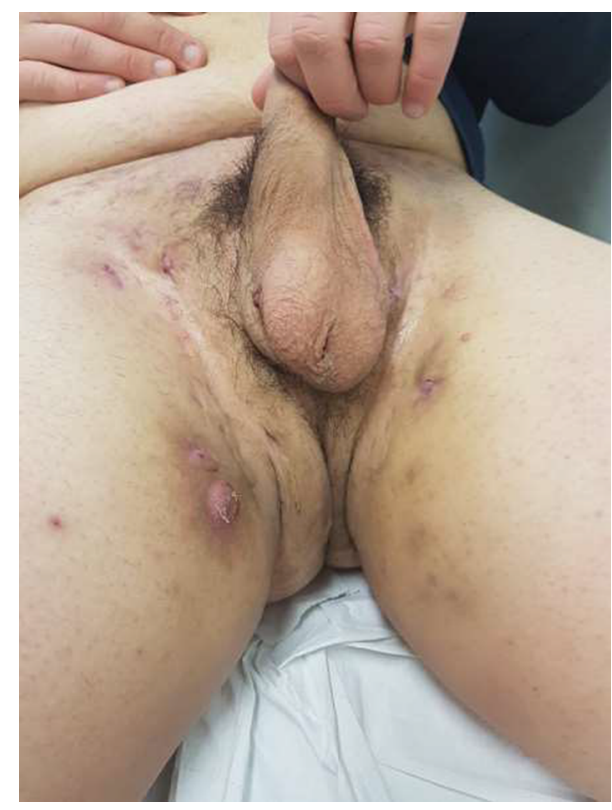

Figure 3 Hidradenitis suppurativa: clinical aspects.

an overt nodule occurs. ${ }^{5}$ Mean duration of a single painful nodule is $7-15$ days. With time, the nodules may rupture, resulting in painful, deep dermal abscesses. After rupture, the lesions often extrude a purulent, foul-smelling discharge. With disease progression, draining sinus tracts, fibrosis, and scarring can be observed. ${ }^{46}$

Primary HS lesions may also present as painful and/or tender erythematous papules $<1 \mathrm{~cm}$ in diameter, as dermal contractures and rope-like elevation of the skin, or as doubleended comedones. ${ }^{47}$ Follicular papules and pustules may be seen in areas associated with HS as well as in other areas; they do not constitute a diagnostic clue for HS. On the but- 
tocks, folliculitis can leave round, slightly depressed scars. The sites affected by HS include, in order of decreasing frequency, axillary, inguinal, perineal and perianal, mammary and inframammary, buttocks, pubic region, chest, scalp, retroauricular, and eyelid..$^{48}$ Patients with anogenital HS may also have disease in the anal canal corresponding to the distribution of apocrine glands and hair follicles in that region.

Chronicity is the hallmark of HS. The disease course is characterized by recurrent flares, as well as pain causing significant quality-of-life impairment. ${ }^{49}$ Patients reported changes in self-perception, daily living activities, mood state, social functioning, and physical discomfort. HS patients experience a quality of life worse than that of patients with alopecia, mild to moderate psoriasis, and several other dermatologic conditions. ${ }^{3}$

Diagnosis of HS is made by clinical observation, and a biopsy is rarely needed. HS can easily be differentiated from other diseases by the age of onset and by the characteristic locations of the lesions. ${ }^{50}$ Table 1 presents the primary differential diagnoses of HS.

\section{Classification and severity assessment}

A clinically relevant staging and disease severity assessment are essential for the development of evidence-based treatments. There are several scoring systems for the assessment of disease severity of HS, including Hurley staging, HS Physician's Global Assessment (PGA), the modified Sartorius score (MSS), and HS Severity Index (HSSI). ${ }^{51-54}$ Each of these assessments has both advantages and limitations in daily practice; to date, there is no gold standard.

\section{Hurley staging system}

This is the simplest and most widely used instrument for HS classification in routine clinical practice. It classifies HS

Table I Differential diagnosis of hidradenitis suppurativa

\begin{tabular}{l}
\hline Differential diagnosis \\
\hline Common abscess \\
Carbuncles \\
Furunculosis \\
Infected Bartholin's gland \\
Inflamed epidermal cysts \\
Pilonidal cyst \\
Scrofuloderma \\
Actinomycosis \\
Lymphogranuloma venereum \\
Crohn's disease
\end{tabular}

into three stages: ${ }^{55}$ 1) stage I: abscess formation, single or multiple, without sinus tracts and cicatrization; 2) stage II: recurrent abscesses with tract formation and cicatrization, single or multiple, widely separated lesions; and 3) stage III: diffuse or near-diffuse involvement, or multiple interconnected tracts and abscesses across the entire area. Although the system is fast and easy, Hurley classification is not suitable for monitoring the efficacy of therapeutic interventions in clinical trials, since the classification is not quantitative.

\section{MSS}

This is a more detailed and dynamic classification system, based on the counting of individual nodules and fistulas within seven anatomical regions. The system, which was developed by Sartorius et al and later modified, is the first disease-specific instrument for dynamically measuring clinical severity of HS. ${ }^{56,57}$ Calculating MSS requires measuring the longest distance between two lesions of the same type within each anatomical region and applying predetermined weights to specific types of lesion characteristics. Disadvantages of the MSS are that the system is time consuming and sometimes difficult to interpret; consequently, MSS is not optimal for evaluating inflammatory manifestations in clinical practice or trials. ${ }^{42}$

\section{HS-PGA}

HS-PGA is relatively easy to use and is frequently used to measure clinical improvement in clinical trials of medical treatments. ${ }^{51}$ It classifies HS severity by counting the number of abscesses, fistulas, and inflammatory and noninflammatory nodules in all skin areas. The system describes six disease stages, increasing in severity on a scale from 1 to 6 (from stage 1: clear, no inflammatory or noninflammatory nodules to stage 6 : severe, $>5$ abscesses or draining fistulas). ${ }^{11,51}$ However, a serious limitation of HS-PGA is that patients could experience clinically important improvement but not gain a meaningful reduction in their HS-PGA score, as patients in the most severe category may show marked heterogeneity.

\section{HSSI}

HSSI is another HS-specific severity index. ${ }^{53,58}$ This score incorporates categorical objective parameters with categorical subjective parameters: body surface area involved, number of skin lesions, pain severity (determined through a visual analog scale), and drainage (determined by the number of dressing changes/working hours). HSSI scores $\geq 13$ indicate severe disease, scores between 8 and 12, moderate disease, and scores between 0 and 7 , mild disease. 


\section{Comorbidities}

Recent studies have proposed defining HS as a systemic disease linked to several comorbidities. ${ }^{59-62}$ Observed comorbidities fall into different classes: obesity and metabolic syndrome (MetS), depression, and inflammatory bowel disease (IBD) ${ }^{63}$ Rates of obesity in HS range from $12 \%$ to $88 \%$, depending on the population. HS disease severity is associated with an elevated body mass index (BMI) ${ }^{64-66} \mathrm{In}$ recent studies, obese patients with HS showed dysregulated adipokine levels, ${ }^{18,67}$ in these patients, macrophages in visceral fat could secrete increased levels of pro-inflammatory cytokines, such as TNF- $\alpha$ and IL- $1 \beta$, which could then exacerbate HS disease activity. ${ }^{3}$

HS patients are at higher risk of MetS and its components. Sabat et al reported an odds ratio (OR) of 4.46 for MetS comparing HS patients with healthy controls; similarly, in this patient population, OR values for central obesity, hypertriglyceridemia, hypo-HDL-cholesterolemia, and hyperglycemia were $5.88,2.24,4.56$, and 4.09 , respectively. ${ }^{68}$ Hence, it is not surprising that HS patients have also shown an increased cardiovascular risk and adverse cardiovascular outcomes in both controls and patients with severe psoriasis. ${ }^{69,70}$ Therefore, clinicians should take into account that HS patients may have $\geq 1$ undiagnosed components of MetS, despite their youth, and initiate appropriate targeted screening. Patients affected by HS may benefit from early dietary interventions aimed at the metabolic comorbidities that may predispose the patient to HS itself, with weight reduction being a secondary benefit.

Patients with HS have a higher risk of developing depression. A cross-sectional study involving 9,619 patients found a higher prevalence of depression (5.9\%) in HS patients relative to controls. ${ }^{71}$ In another study, the Dermatology Life Quality Index value was significantly higher for HS patients than for the control patients $(8.4 \pm 7.5$ vs $4.3 \pm 5.6 ; P<0.0001){ }^{72}$

Patients with HS also have a higher prevalence of gastrointestinal disease. The prevalence of IBD is $4-8$ times higher in HS patients than in the general population, although there is no association with any distinct HS subtype ${ }^{63}$ Moreover, compared to the general population, patients with IBD are 9 times more likely to develop HS (incidence rate ratio of 8.9). ${ }^{73}$ Perianal disease is the most common feature in patients with both HS and Crohn disease, while the majority of ulcerative colitis patients who developed HS did so after colectomy, in the setting of pouchitis. ${ }^{74} \mathrm{HS}$ has also been reported to be associated with pyoderma gangrenosum (PG) which is also frequently linked to IBD. ${ }^{75} \mathrm{~A}$ multicenter retrospective study conducted in 2010 reported 11 cases of patients with
HS and PG: HS usually predated PG with a mean time of 2.5 years prior to PG often having a severe, refractory course. ${ }^{75}$ Moreover, three syndromes with PG and HS are reported in the literature. Each of these syndromes consists of the triad of PG, acne conglobata, and HS, and are differentiated clinically by the presence/absence and/or type of articular involvement: PAPASH (PG, acne, HS, and pyogenic arthritis), PASS (PG, acne conglobata, HS, and axial spondyloarthropathy), and PASH (PG, acne conglobata, and HS). ${ }^{70}$ Other rheumatologic conditions may also be linked to HS. ${ }^{76,77}$ A multicenter, observational study of 640 patients with HS showed that 184 (28.8\%) had musculoskeletal symptoms, 43 (6.9\%) had evidence of arthritis, enthesitis, or inflammatory back pain, and 24 (3.7\%) were diagnosed with spondyloarthropathy after evaluation by X-ray, magnetic resonance, and a rheumatologist. ${ }^{76}$ Usually, HS preceded joint pain in $90 \%$ of cases by a mean of 3.6 years. In a retrospective study of 29 cases of HS and spondyloarthropathy, involvement of axial (69\%) and peripheral (86\%) joints was common with the knee being reported as the most frequently affected peripheral joint (59\%). ${ }^{77}$ An association between rheumatologic joint conditions, namely spondyloarthropathies, and synovitis, arthritis, pustulosis, hyperostosis, osteitis syndrome has also been seen in conjunction with HS. ${ }^{70,76}$ Moreover, due to common shared etiopathogenetic factors such as follicular occlusion from infundibular hyperkeratosis and follicular epithelium hyperplasia, HS has also been possibly reported in conjunction with other follicular occlusion disorders like acne conglobata, dissecting cellulitis of the scalp, and sinus pilonidalis, ${ }^{70}$ creating the follicular occlusion tetrad: HS, acne conglobata, dissecting cellulitis, and pilonidal cysts. ${ }^{78}$ Finally, as regards HS-related malignancies risk, squamous cell carcinoma (SCC) has been reported to possibly arise within or neighboring HS lesions (from $1 \%$ to $3.1 \%$ of evaluated HS patients).$^{79}$ The risk seems to be more frequent in gluteal, perianal, and perineal areas due to chronic inflammation of HS, impaired cellular immunity, and the presence of the human papillomavirus. ${ }^{80}$ Therefore, clinicians should raise their index of suspicion for this malignancy and lower their biopsy threshold in HS patients to prevent or minimize SCC metastasis especially when ulcerative lesions, chronic wounds, nodules, or ulcerative nodules arise and do not show response to common antibiotic or immunosuppressive treatments used in HS patients.

\section{Treatment}

HS treatment choices should be determined by disease severity and its individual subjective impact. The degree of HS 
clinical involvement is usually ascertained according to the three-stage Hurley system described above. ${ }^{55}$

\section{Topical antibiotics}

Clindamycin is the only antibiotic that has been studied as a topical agent for HS. ${ }^{81,82}$ The most significant effect was seen with superficial lesions (folliculitis, papules, and pustules); in contrast, the treatment efficacy was poor with deep lesions (nodules and abscesses). As a topical treatment, clindamycin seems to be indicated only in localized Hurley stage I or mild stage II disease. ${ }^{11}$

\section{Systemic treatments}

Systemic treatment is indicated when more severe or widely spread lesions are present (moderate to severe disease). ${ }^{11}$

\section{Clindamycin-rifampicin}

In widespread Hurley stage I or mild stage II disease, the combined use of systemic clindamycin and systemic rifampicin (300 mg of clindamycin b.i.d. given in combination with rifampicin [600 mg daily given as either 1 or 2 doses] for 10 weeks) has proved beneficial, with variable results. ${ }^{83-87}$ In a study conducted by van der Zee et al, $47 \%$ of HS patients receiving systemic clindamycin/rifampicin treatment reported total remission after 10 weeks, while an additional $35 \%$ of subjects experienced at least some improvement, whereas another survey reported that 70/116 patients $(\sim 70 \%)$ had significant improvement after 10 weeks of treatment. ${ }^{83,85}$ A very recent, prospective, hospital-based study reported clinical response in 19 patients (73\%) after 12 weeks of treatment, supporting the efficacy and tolerability of this combination therapy. Response was associated only with female sex and not with BMI, Hurley stage, or lesion location. The authors also reported that there was sustained efficacy in $7(41 \%)$ patients at the 1-year follow-up, whereas 10 subjects $(59 \%)$ had disease relapse after a mean time of 4.2 months. ${ }^{87}$

\section{Tetracycline}

Tetracycline (500 mg b.i.d.) has not proven effective compared to topical clindamycin in widespread Hurley stage I or mild stage II disease. ${ }^{82}$

\section{Rifampicin-moxifloxacin-metronidazole}

Rifampicin $10 \mathrm{mg} / \mathrm{kg}$ once daily, moxifloxacin $400 \mathrm{mg}$ daily, and metronidazole $500 \mathrm{mg}$ t.i.d. for 6 weeks followed by rifampicin-moxifloxacin therapy has been shown to be effective, with 16 of 28 patients $(57.1 \%)$ with long-lasting refractory HS achieving complete remission and 14 of 16 patients $(87.5 \%)$ with Hurley stage I or II disease achieving complete remission. ${ }^{88}$

\section{Ertapenem}

A study showed that ertapenem $1 \mathrm{~g}$ daily intravenously for 6 weeks was able to decrease the median Sartorius score from 49.5 to 19.0 , reflecting a significant decrease in the number and clinical severity of active HS areas in a group of 30 patients with severe HS. Altogether, 67\% (29/43) and 26\% (13/50) of Hurley stage I and II patients' body areas reached clinical remission after ertapenem, respectively. ${ }^{89}$

\section{Acitretin}

Acitretin is indicated for early HS stages (Hurley I or mild II); however, it seems reasonable that this medication could also be advocated in the chronic stages of HS with recurrent abscesses with sinus tracts (even interconnected) and/or scarring. ${ }^{90-93}$ Daily doses of $0.25-0.88 \mathrm{mg} / \mathrm{kg}$ for $3-12$ months have been used in studies concerning acitretin therapy in HS patients. ${ }^{90,91}$ Studies involving acitretin treatment comprised in total 46 patients, reporting a moderate to high response rate with significant improvements in 28 of 46 subjects $(60.9 \%)$ after therapy ${ }^{92-97}$ However, a recent 5 -year retrospective study conducted in a tertiary medical center (14 patients) showed that acitretin monotherapy was ineffective for the treatment of Hurley stage II-III HS with acitretin being more effective when used as an adjuvant to other systemic medications. ${ }^{92}$

\section{Cyclosporine $A$}

Beneficial effects of cyclosporine are reported in limited cases. ${ }^{98-100}$ A recent exploratory 4-year retrospective review performed at three departments of dermatology with a special interest in HS showed that 9/18 (50\%) patients treated with cyclosporine reported some benefit (mainly slight improvement). ${ }^{101}$ Therefore, use of cyclosporine should be reserved for cases where failure of response to standard first-, second-, and third-line therapies occurs until further evidence is available. ${ }^{11}$

\section{Dapsone}

Several studies involving oral dapsone have been published with mixed results. ${ }^{102-104}$ The most important study was conducted in 2011. It involved $24 \mathrm{HS}$ patients with reported improvement in only $38 \%$ of cases, and none of the 4 cases with severe disease experiencing any kind of improvement. Rapid recurrence of disease at the cessation of treatment occurred. ${ }^{102}$ Thus, it seems that dapsone may be best used in 
stage I or sometimes in mild stage II patients, preferably in combination with other agents.

\section{Isotretinoin}

The results of isotretinoin therapy in HS have not been encouraging. Several studies showed that oral isotretinoin has only little effect on HS (eg, in a retrospective study on 358 patients, Soria et al showed that only $16.1 \%$ of patients experienced any improvement). ${ }^{105-107}$ Isotretinoin has maximal effect on sebaceous gland activity; however, sebum production is normal in HS. Consequently, it is unsurprising that isotretinoin therapy is ineffective. ${ }^{108}$

\section{Biologics}

Recent studies have shown that adalimumab and infliximab, two different monoclonal antibodies against TNF- $\alpha$, are effective in the treatment of moderate to severe HS (Hurley II-III), with improvement in the patient's quality of life, with adalimumab being more tolerable. ${ }^{109-111}$ As regards infliximab, a cumulative response rate of $58 \%$ (improvement $\geq 50 \%$ in 42 patients) has been reported in case reports with 73 patients with moderate to severe HS. ${ }^{12-121}$ Only a single randomized controlled trial (RCT), Phase II crossover study on 38 HS patients treated with infliximab was published in 2010 and no additional Phase III RCT studies have been published so far. $^{58}$

Infliximab ( $5 \mathrm{mg} / \mathrm{kg}$ body weight) is administered intravenously over a period of 2 hours on day $0,2,6$, and then regularly every 8 weeks. ${ }^{11,51}$ There are different rates of response to adalimumab reported in case series and in a current, prospective controlled study. Adalimumab, a human monoclonal antibody that binds to and neutralizes TNF- $\alpha$, is the first Food and Drug Administration (FDA)approved treatment for moderate to severe HS in adults. ${ }^{110}$ Administration of adalimumab with a cumulative response rate of $58 \%$ (improvement $\geq 50 \%$ in 23 patients) has been reported in case reports with 42 patients with moderate to severe HS. ${ }^{53,122-125}$ Two Phase III, randomized, double-blind clinical trials (PIONEER I and PIONEER II) to assess the safety and efficacy of adalimumab in the treatment of patients with moderate-severe HS were recently completed. ${ }^{126-128}$ Both the studies were multicentered, 36-week trials with two double-blind, placebo-controlled periods (12-week period 1 and 24-week period 2). In period 1, patients were randomly assigned in a $1: 1$ ratio to $40 \mathrm{mg}$ of adalimumab weekly or matching placebo for 12 weeks. In period 2, patients were reassigned to adalimumab at a weekly or every-other-week dose or to placebo for 24 weeks.
Particularly, 307 and 326 patients were enrolled in PIONEER I and PIONEER II studies, respectively. Inclusion criteria included adults (between 18 and 99 years of age) with a diagnosis of HS for at least 1 year and the presence of at least two areas exhibiting HS lesions with at least one categorized as Hurley stage II or stage III, stable HS for at least 60 days prior to screening and baseline visits, previous inadequate response to other HS treatments, and total abscess and inflammatory nodule count of $\geq 3$ at baseline. Primary efficacy outcome of $50 \%$ reduction in abscess and inflammatory nodule count was seen in $41.8 \%$ and $58.9 \%$ of participants receiving adalimumab in PIONEER I and PIONEER II studies, respectively, showing substantial improvement compared with placebo groups in both the trials (26.0\% and $27.6 \%$, respectively). Serious adverse events in period 1 (excluding worsening of underlying disease) occurred in $1.3 \%$ of patients receiving adalimumab and $1.3 \%$ of those receiving placebo in PIONEER I and in $1.8 \%$ and $3.7 \%$ of patients in PIONEER II. In period 2, the rates of serious adverse events were $\leq 4.6 \%$ in all the groups in both studies, with no significant differences between placebo and treatment groups. On the other hand, another biologic drug, ustekinumab, a monoclonal antibody directed against IL-12 and IL-23, has been shown to reduce the mean MSS with a $46.3 \%$ improvement in 12 patients with moderate to severe (Hurley stage II-III) disease treated with 45 or $90 \mathrm{mg}$ ustekinumab (depending on body weight) at weeks $0,4,16$, and $28 .{ }^{129}$ However, further studies are needed to evaluate its efficacy in HS patients because, apart from the study of Blok et al, its use in HS has been described only in case reports or very small case series. ${ }^{130-133}$

\section{Conclusion}

HS is a chronic inflammatory skin disease that can have a debilitating effect on a patient's social activities, work activities, and overall quality of life. The disease is multifactorial, with interplay between multiple genetic, immunological, behavioral, and endocrine factors playing a key role in its development. HS can greatly impact patients' quality of life and social and work activities due to frequent disease relapses with painful and foul-smelling lesions. Therefore, prompt treatment is required to reduce and limit HS burden. Nevertheless, therapeutic weapons against HS include several treatments; most of them are used off-label, with adalimumab being the only FDA-approved drug for moderate to severe HS. HS patients often need a multidisciplinary approach, incorporating both medical and surgical treatments in addition to lifestyle modification. HS remains a challenging 
disease that is difficult to treat. Further studies are needed to ascertain whether certain genetic, clinical, or phenotypic factors may predict or guide treatments outcomes.

\section{Disclosure}

The authors report no conflicts of interest in this work.

\section{References}

1. Kurzen H, Kurokawa I, Jemec GB, et al. What causes hidradenitis suppurativa? Exp Dermatol. 2008;17:455-472.

2. Naldi L. Epidemiology. In: Jemec G, Revuz J, Leyden JJ, editors. Hidradenitis Suppurative. Berlin: Springer; 2006:58-64.

3. Alikhan A, Lynch PJ, Eisen DB. Hidradenitis suppurativa: a comprehensive review. J Am Acad Dermatol. 2009;60(4):539-561.

4. Revuz JE, Canoui-Poitrine F, Wolkenstein P, et al. Prevalence and factors associated with hidradenitis suppurativa: results from two case-control studies. J Am Acad Dermatol. 2008;59:596-601.

5. Jemec GB, Heidenheim M, Nielsen NH. The prevalence of hidradenitis suppurativa and its potential precursor lesions. J Am Acad Dermatol. 1996;35:191-194.

6. Jemec GB. The symptomatology of hidradenitis suppurativa in women. Br J Dermatol. 1988;119:345-350.

7. Vazquez BG, Alikhan A, Weaver AL, Wetter DA, Davis MD. Incidence of hidradenitis suppurativa and associated factors: a populationbased study of Olmsted County, Minnesota. J Invest Dermatol. 2013;133:97-103.

8. Cosmatos I, Matcho A, Weinstein R, Montgomery MO, Stang P. Analysis of patient claims data to determine the prevalence of hidradenitis suppurativa in the United States. J Am Acad Dermatol. 2013;68: 412-419.

9. Margesson LJ, Danby FW. Hidradenitis suppurativa. Best Pract Res Clin Obstet Gynaecol. 2014;28:1013-1027.

10. Esmann S, Dufour DN, Jemec GB. Questionnaire-based diagnosis of hidradenitis suppurativa: specificity, sensitivity and positive predictive value of specific diagnostic questions. Br J Dermatol. 2010;163:102-106.

11. Zouboulis CC, Desai N, Emtestam L, et al. European S1 guideline for the treatment of hidradenitis suppurativa/acne inversa. J Eur Acad Dermatol Venereol. 2015;29:619-644.

12. de Winter K, van der Zee HH, Prens EP. Is mechanical stress an important pathogenic factor in hidradenitis suppurativa? Exp Dermatol. 2012;21:176-177.

13. Schrader AM, Deckers IE, van der Zee HH, Boer J, Prens EP. Hidradenitis suppurativa: a retrospective study of 846 Dutch patients to identify factors associated with disease severity. $\mathrm{JAm}$ Acad Dermatol. 2014;71:460-467.

14. Fitzsimmons JS, Guilbert PR. A family study of hidradenitis suppurativa. J Med Genet. 1985;22:367-373.

15. Pink AE, Simpson MA, Desai N, et al. Mutations in the gamma-secretase genes NCSTN, PSENEN, and PSEN1 underlie rare forms of hidradenitis suppurativa (acne inversa). J Invest Dermatol. 2012;132:2459-2461.

16. Wang B, Yang W, Wen W, et al. Gamma-secretase gene mutations in familial acne inversa. Science. 2010;330:1065.

17. Pink AE, Simpson MA, Desai N, Trembath RC, Barker JN. Gammasecretase mutations in hidradenitis suppurativa: new insights into disease pathogenesis. J Invest Dermatol. 2013;133:601-607.

18. Scheinfeld N. Hidradenitis suppurativa: a practical review of possible medical treatments based on over 350 hidradenitis patients. Dermatol Online J. 2013;19:1.

19. Prens E, Deckers I. Pathophysiology of hidradenitis suppurativa: an update. JAm Acad Dermatol. 2015;73(5 Suppl 1):S8-S11.

20. Jemec GB, Thomsen BM, Hansen U. The homogeneity of hidradenitis suppurativa lesions. A histological study of intra-individual variation. APMIS. 1997;105:378-383.
21. Jemec GB, Hansen U. Histology of hidradenitis suppurativa. JAm Acad Dermatol. 1996;34:994-999.

22. von Laffert M, Helmbold P, Wohlrab J, Fiedler E, Stadie V, Marsch WC. Hidradenitis suppurativa (acne inversa): early inflammatory events at terminal follicles and at interfollicular epidermis. Exp Dermatol. 2010;19:533-537.

23. Boer J, Weltevreden EF. Hidradenitis suppurativa or acne inversa. A clinicopathological study of early lesions. Br J Dermatol. 1996;135: $72-75$.

24. Kamp S, Fiehn AM, Stenderup K, et al. Hidradenitis suppurativa: a disease of the absent sebaceous gland? Sebaceous gland number and volume are significantly reduced in uninvolved hair follicles from patients with hidradenitis suppurativa. Br J Dermatol. 2011;164(5): 1017-1022.

25. Kathju S, Lasko LA, Stoodley P. Considering hidradenitis suppurativa as a bacterial biofilm disease. FEMS Immunol Med Microbiol. 2012;65(2):385-389.

26. Guet-Revillet H, Coignard-Biehler H, Jais JP, et al. Bacterial pathogens associated with hidradenitis suppurativa, France. Emerg Infect Dis. 2014;20(12):1990-1998.

27. Matusiak L, Bieniek A, Szepietowski JC. Bacteriology of hidradenitis suppurativa - which antibiotics are the treatment of choice? Acta Derm Venereol. 2014;94(6):699-702.

28. Hofmann SC, Saborowski V, Lange S, Kern WV, Bruckner-Tuderman L, Rieg S. Expression of innate defense antimicrobial peptides in hidradenitis suppurativa. J Am Acad Dermatol. 2012;66:966-974.

29. Emelianov VU, Bechara FG, Gläser R, et al. Immunohistological pointers to a possible role for excessive cathelicidin (LL-37) expression by apocrine sweat glands in the pathogenesis of hidradenitis suppurativa/ acne inversa. Br J Dermatol. 2012;166:1023-1034.

30. Bechara FG, Sand M, Skrygan M, Kreuter A, Altmeyer P, Gambichler T. Acne inversa: evaluating antimicrobial peptides and proteins. Ann Dermatol. 2012;24:393-397.

31. Mammucari C, Tommasi di Vignano A, Sharov AA, et al. Integration of Notch 1 and calcineurin/NFAT signaling pathways in keratinocyte growth and differentiation control. Dev Cell. 2005;8:665-676.

32. Melnik BC, Plewig G. Impaired Notch-MKP-1 signalling in hidradenitis suppurativa: an approach to pathogenesis by evidence from translational biology. Exp Dermatol. 2013;22:172-177.

33. Rangarajan A, Talora C, Okuyama R, et al. Notch signaling is a direct determinant of keratinocyte growth arrest and entry into differentiation. EMBO J. 2001;20:3427-3436.

34. Pan Y, Lin MH, Tian X, et al. Gamma-secretase functions through Notch signaling to maintain skin appendages but is not required for their patterning or initial morphogenesis. Dev Cell. 2004;7:731-743.

35. van der Zee HH, Laman JD, de Ruiter L, Dik WA, Prens EP. Adalimumab (antitumour necrosis factor- $\alpha$ ) treatment of hidradenitis suppurativa ameliorates skin inflammation: an in situ and ex vivo study. Br J Dermatol. 2012;166:298-305.

36. Hunger RE, Surovy AM, Hassan AS, Braathen LR, Yawalkar N. Toll-like receptor 2 is highly expressed in lesions of acne inversa and colocalizes with C-type lectin receptor. Br J Dermatol. 2008;158:691-697.

37. Re F, Strominger JL. Toll-like receptor 2 (TLR2) and TLR4 differentially activate human dendritic cells. J Biol Chem. 2001;276:37692-37699.

38. Schlapbach C, Hänni T, Yawalkar N, Hunger RE. Expression of the IL-23/Th17 pathway in lesions of hidradenitis suppurativa. $J$ Am Acad Dermatol. 2011;65:790-798.

39. Giamarellos-Bourboulis EJ, Antonopoulou A, Petropoulou C, et al. Altered innate and adaptive immune responses in patients with hidradenitis suppurativa. Br J Dermatol. 2007;156:51-56.

40. Zhang Q, Wang C, Liu Z, et al. Notch signal suppresses Toll-like receptor-triggered inflammatory responses in macrophages by inhibiting extracellular signal-regulated kinase 1/2-mediated nuclear factor $\kappa B$ activation. J Biol Chem. 2012;287:6208-6217.

41. Mozeika E, Pilmane M, Nürnberg BM, Jemec GB. Tumour necrosis factor-alpha and matrix metalloproteinase-2 are expressed strongly in hidradenitis suppurativa. Acta Derm Venereol. 2013;93:301-304. 
42. van der Zee HH, Laman JD, Boer J, Prens EP. Hidradenitis suppurativa: viewpoint on clinical phenotyping, pathogenesis and novel treatments. Exp Dermatol. 2012;21:735-739.

43. Kathju S, Lasko L, Stoodley P. Considering hidradenitis suppurativa as a bacterial biofilm disease. FEMS Immunol Med Microbiol. 2012;65:385-389.

44. Jahns AC, Killasli H, Nosek D, et al. Microbiology of hidradenitis suppurativa (acne inversa): a histological study of 27 patients. APMIS 2014;122:804-809.

45. Yu CC, Cook MG. Hidradenitis suppurativa: a disease of follicular epithelium, rather than apocrine glands. Br J Dermatol. 1990;122:763-769.

46. Esmann S, Jemec GB. Psychosocial impact of hidradenitis suppurativa: a qualitative study. Acta Derm Venereol. 2011;91:328-332.

47. Brown TJ, Rosen T, Orengo IF. Hidradenitis suppurativa. South Med J. 1998;91:1107-1114.

48. Slade DEM, Powell BW, Mortimer PS. Hidradenitis suppurativa: pathogenesis and management. Br J Plast Surg. 2003;56:451-461.

49. Shalom G, Freud T, Harman-Boehm I, Polishchuk I, Cohen AD. Hidradenitis suppurativa and metabolic syndrome: a comparative crosssectional study of 3207 patients. Br J Dermatol. 2015;173(2):464-470.

50. Revuz J. Hidradenitis suppurativa. J Eur Acad Dermatol Venereol. 2009;23(9):985-998.

51. Kimball AB, Kerdel F, Adams D, et al. Adalimumab for the treatment of moderate to severe hidradenitis suppurativa: a parallel randomized trial. Ann Intern Med. 2012;157:846-855.

52. Sartorius K, Killasli H, Heilborn J, Jemec GB, Lapins J, Emtestam L. Interobserver variability of clinical scores in hidradenitis suppurativa is low. Br J Dermatol. 2010;162:1261-1268.

53. Amano M, Grant A, Kerdel FA. A prospective open-label clinical trial of adalimumab for the treatment of hidradenitis suppurativa. Int $J$ Dermatol. 2010;49:950-955.

54. Jemec GB. Biomarkers in hidradenitis suppurativa. Br J Dermatol. 2013;168:1151-1153.

55. Hurley HJ. Axillary hyperhidrosis, apocrine bromhidrosis, hidradenitis suppurativa, and familial benign pemphigus: surgical approach. In: Roenigk RK, Roenigk HH, editors. Dermatologic Surgery. New York: Marcel Dekker; 1996:623-645.

56. Sartorius K, Emtestam L, Jemec GB, Lapins J. Objective scoring of hidradenitis suppurativa reflecting the role of tobacco smoking and obesity. Br J Dermatol. 2009;161:831-839.

57. Sartorius K, Lapins J, Emtestam L, Jemec GB. Suggestions for uniform outcome variables when reporting treatment effects in hidradenitis suppurativa. Br J Dermatol. 2003;149:211-213.

58. Grant A, Gonzalez T, Montgomery MO, Cardenas V, Kerdel FA Infliximab therapy for patients with moderate to severe hidradenitis suppurativa: a randomized, double-blind, placebo-controlled crossover trial. J Am Acad Dermatol. 2010;62:205-217.

59. Pascoe VL, Kimball AB. Hidradenitis suppurativa: current progress and future questions. JAMA Dermatol. 2014;150:1263-1264.

60. Gold DA, Reeder VJ, Mahan MG, Hamzavi IH. The prevalence of metabolic syndrome in patients with hidradenitis suppurativa. $J \mathrm{Am}$ Acad Dermatol. 2014;70:699-703.

61. Shlyankevich J, Chen AJ, Kim GE, Kimball AB. Hidradenitis suppurativa is a systemic disease with substantial comorbidity burden: a chart-verified case-control analysis. J Am Acad Dermatol. 2014;71(6):1144-1150.

62. Miller IM, Ellervik C, Vinding GR, et al. Association of metabolic syndrome and hidradenitis suppurativa. JAMA Dermatol. 2014;150:1273-1280.

63. Deckers IE, Benhadou F, Koldijk MJ, et al. Inflammatory bowel disease is associated with hidradenitis suppurativa: results from a multicenter cross-sectional study. J Am Acad Dermatol. 2017;76(1):49-53.

64. Napolitano M, Megna M, Monfrecola G. Insulin resistance and skin diseases. Scientific World J. 2015;2015:479354.

65. Bettoli V, Naldi L, Cazzaniga S, et al. Overweight, diabetes and disease duration influence clinical severity in hidradenitis suppurativa-acne inversa. Evidence from the national Italian registry. $\mathrm{Br} J$ Dermatol. 2016;174(1):195-197.
66. Monfrecola G, Balato A, Caiazzo G, et al. Mammalian target of rapamycin, insulin resistance and hidradenitis suppurativa: a possible metabolic loop. J Eur Acad Dermatol Venereol. 2016;30(9):1631-1633.

67. Tian G, Liang JN, Wang ZY, Zhou D. Emerging role of leptin in rheumatoid arthritis. Clin Exp Immunol. 2014;177:557-570.

68. Sabat R, Chanwangpong A, Schneider-Burrus S, et al. Increased prevalence of metabolic syndrome in patients with acne inversa. PLoS One. 2012; 7:e31810.

69. Egeberg A, Gislason GH, Hansen PR. Risk of major adverse cardiovascular events and all-cause mortality in patients with hidradenitis suppurativa. JAMA Dermatol. 2016;152(4):429-434.

70. Miller IM, McAndrew RJ, Hamzavi I. Prevalence, risk factors, and comorbidities of hidradenitis suppurativa. Dermatol Clin. 2016;34(1):7-16.

71. Shavit E, Dreiher J, Freud T, Halevy S, Vinker S, Cohen AD. Psychiatric comorbidities in 3207 patients with hidradenitis suppurativa. J Eur Acad Dermatol Venereol. 2015;29:371-376.

72. Onderdijk AJ, van der Zee HH, Esmann S, et al. Depression in patients with hidradenitis suppurativa. J Eur Acad Dermatol Venereol. 2013;27(4):473-478.

73. Yadav S, Singh S, Edakkanambeth Varayil J, et al. Hidradenitis suppurativa in patients with inflammatory bowel disease: a populationbased cohort study in Olmsted County, Minnesota. Clin Gastroenterol Hepatol. 2016;14(1):65-70.

74. Kamal N, Cohen BL, Buche S, Delaporte E, Colombel JF. Features of patients with Crohn's disease and hidradenitis suppurativa. Clin Gastroenterol Hepatol. 2016;14(1):71-79.

75. Hsiao JL, Antaya RJ, Berger T, Maurer T, Shinkai K, Leslie KS. Hidradenitis suppurativa and concomitant pyoderma gangrenosum: a case series and literature review. Arch Dermatol. 2010;146(11):1265-1270.

76. Richette $\mathrm{P}$, Molto A, Viguier M, et al. Hidradenitis suppurativa associated with spondyloarthritis - results from a multicenter national prospective study. J Rheumatol. 2014;41:490-494.

77. Bhalla R, Sequeira W. Arthritis associated with hidradenitis suppurativa. Ann Rheum Dis. 1994;53:64-66.

78. Vasanth V, Chandrashekar BS. Follicular occlusion tetrad. Indian Dermatol Online J. 2014;5:491-493.

79. Constantinou C, Widom K, Desantis J, Obmann M. Hidradenitis suppurativa complicated by squamous cell carcinoma. Am Surg. 2008;74(12):1177-1181.

80. Scheinfeld N. A case of a patient with stage III familial hidradenitis suppurativa treated with 3 courses of infliximab and died of metastatic squamous cell carcinoma. Dermatol Online J. 2014;20(3).

81. Clemmensen OJ. Topical treatment of hidradenitis suppurativa with clindamycin. Int J Dermatol. 1983;22:325-328.

82. Jemec GBE, Wendelboe P. Topical clindamycin versus systemic tetracycline in the treatment of hidradenitis suppurativa. J Am Acad Dermatol. 1998;39:971-974.

83. Gener G, Canoui-Poitrine F, Revuz JE, et al. Combination therapy with clindamycin and rifampicin for hidradenitis suppurativa: a series of 116 consecutive patients. Dermatology. 2009;219:148-154

84. Mendonca CO, Griffiths CE. Clindamycin and rifampicin combination therapy for hidradenitis suppurativa. $B r J$ Dermatol. 2006;154: 977-978.

85. van der Zee HH, Boer J, Prens EP, Jemev JB. The effect of combined treatment with oral clindamycin and oral rifampicin in patients with hidradenitis suppurativa. Dermatology. 2009;219:143-147.

86. Bettoli V, Zauli S, Borghi A, et al. Oral clindamycin and rifampicin in the treatment of hidradenitis suppurativa-acne inversa: a prospective study on 23 patients. J Eur Acad Dermatol Venereol. 2014;28: $125-126$.

87. Dessinioti C, Zisimou C, Tzanetakou V, Stratigos A, Antoniou C. Oral clindamycin and rifampicin combination therapy for hidradenitis suppurativa: a prospective study and 1-year follow-up. Clin Exp Dermatol. 2016;41(8):852-857.

88. Join-Lambert O, Coignard H, Jais JP, et al. Efficacy of rifampin-moxifloxacin-metronidazole combination therapy in hidradenitis suppurativa. Dermatology. 2011;222(1):49-58. 
89. Join-Lambert O, Coignard-Biehler H, Jais JP, et al. Efficacy of ertapenem in severe hidradenitis suppurativa: a pilot study in a cohort of 30 consecutive patients. J Antimicrob Chemother. 2016;71(2):513-520.

90. Meixner D, Schneider S, Krause M, Sterry W. Acne inversa. J Dtsch Dermatol Ges. 2008;6:189-196.

91. Boer J, Nazary M. Long-term results of acitretin therapy for hidradenitis suppurativa. Is acne inversa also a misnomer? $\mathrm{Br} J$ Dermatol. 2011;164:170-175.

92. Matusiak L, Bieniek A, Szepietowski JC. Acitretin in hidradenitis suppurativa treatment - own experiences. Przegl Dermatol. 2012;99:356-357.

93. Tan MG, Shear NH, Walsh S, Alhusayen R. Acitretin: monotherapy or combined therapy for hidradenitis suppurativa? J Cutan Med Surg. 2016;21(1):48-53.

94. Chow ET, Mortimer PS. Successful treatment of hidradenitis suppurativa and retroauricular acne with etretinate. $\mathrm{Br} J$ Dermatol. 1992;126:415.

95. Hogan DJ, Light MJ. Successful treatment of hidradenitis suppurativa with acitretin. J Am Acad Dermatol. 1988;19:355-356.

96. Scheman AJ. Nodulocystic acne and hidradenitis suppurativa treated with acitretin: a case report. Cutis. 2002;69:287-288.

97. Vahlquist A, Griffiths W. Retinoid therapy in hidradenitis suppurativa - a report of a case. Retinoids Today Tom. 1990;18:28-30.

98. Gupta AK, Ellis CN, Nickoloff BJ, et al. Oral cyclosporine in the treatment of inflammatory and noninflammatory dermatoses. A clinical and immunopathologic analysis. Arch Dermatol. 1990;126:339-350.

99. Rose RF, Goodfield MJ, Clark SM. Treatment of recalcitrant hidradenitis suppurativa with oral ciclosporin. Clin Exp Dermatol. 2006;31:154-155.

100. Buckley DA, Rogers S. Cyclosporin-responsive hidradenitis suppurativa. J R Soc Med. 1995;88:289-290.

101. Anderson MD, Zauli S, Bettoli V, Boer J, Jemec GB. Cyclosporine treatment of severe hidradenitis suppurativa - a case series. J Dermatolog Treat. 2016;27(3):247-250.

102. Yazdanyar S, Boer J, Ingvarsson G, Szepietowski JC, Jemec GB. Dapsone therapy for hidradenitis suppurativa: a series of 24 patients. Dermatology. 2011;222:342-346.

103. Kaur MR, Lewis HM. Hidradenitis suppurativa treated with dapsone: a case series of five patients. J Dermatolog Treat. 2006;17:211-213.

104. Hofer T, Itin PH. [Acne inversa: a dapsone-sensitive dermatosis]. Hautarzt. 2001;52:989-992. German.

105. Soria A, Canoui-Poitrine F, Wolkenstein P, et al. Absence of efficacy of oral isotretinoin in hidradenitis suppurativa: a retrospective study based on patients' outcome assessment. Dermatology. 2009;218:134-135.

106. Boer J, Mirjan JP, Gemert V. Long-term results of isotretinoin in the treatment of 68 patients with hidradenitis suppurativa. J Am Acad Dermatol. 1999;40:73-76.

107. Norris JF, Cunliffe WJ. Failure of treatment of familial widespread hidradenitis suppurativa with isotretinoin. Clin Exp Dermatol. 1986;11:579-583.

108. Jemec GGE, Gniadecka M. Sebum excretion in hidradenitis suppurativa. Dermatology. 1997;194:325-328.

109. Haslund P, Lee RA, Jemec GB. Treatment of hidradenitis suppurativa with tumour necrosis factor-alpha inhibitors. Acta Derm Venereol. 2009;89:595-600.

110. Megna M, Bettoli V, Chimenti S, et al. Hidradenitis suppurativa: guidelines of the Italian Society of Dermatology and Venereology (SIDeMaST) for the use of anti-TNF- $\alpha$ agents. $G$ Ital Dermatol Venereol. 2015;150(6):731-739.

111. Shuja F, Chan CS, Rosen T. Biologic drugs for the treatment of hidradenitis suppurativa: an evidence-based review. Dermatol Clin. 2010;28:511-524.

112. van Rappard DC, Mooij JE, Baeten DL, Mekkes JR. New-onset polyarthritis during successful treatment of hidradenitis suppurativa with infliximab. Br J Dermatol. 2011;165:194-198.

113. Brunasso AM, Delfino C, Massone C. Hidradenitis suppurativa: are tumour necrosis factor-alpha blockers the ultimate alternative? $\mathrm{Br} J$ Dermatol. 2008;159:761-763.
114. Delage M, Samimi M, Atlan M, Machet L, Lorette G, Maruani A. Efficacy of infliximab for hidradenitis suppurativa: assessment of clinical and biological inflammatory markers. Acta Derm Venereol. 2011;91:169-171.

115. Fardet L, Dupuy A, Kerob D, et al. Infliximab for severe hidradenitis suppurativa: transient clinical efficacy in 7 consecutive patients. J Am Acad Dermatol. 2007;56:624-628.

116. Fernandez-Vozmediano JM, Armario-Hita JC. Infliximab for the treatment of hidradenitis suppurativa. Dermatology. 2007;215:41-44.

117. Lasocki A, Sinclair R, Foley P, Saunders H. Hidradenitis suppurativa responding to treatment with infliximab. Australas J Dermatol. 2010;51:186-190.

118. Mekkes JR, Bos JD. Long-term efficacy of a single course of infliximab in hidradenitis suppurativa. Br J Dermatol. 2008;158:370-374.

119. Paradela S, Rodriguez-Lojo R, Fernandez-Torres R, Arévalo P, Fonseca E. Long-term efficacy of infliximab in hidradenitis suppurativa. J Dermatolog Treat. 2012;23:278-283.

120. Pedraz J, Dauden E, Perez-Gala S, Goiriz-Valdés R, Fernández-Peñas P, García-Diez A. [Hidradenitis suppurativa. Response to treatment with infliximab]. Actas Dermosifiliogr. 2007;98:325-331. Spanish.

121. Usmani N, Clayton TH, Everett S, Goodfield MD. Variable response of hidradenitis suppurativa to infliximab in four patients. Clin Exp Dermatol. 2007;32:204-205.

122. Arenbergerova M, Gkalpakiotis S, Arenberger P. Effective long-term control of refractory hidradenitis suppurativa with adalimumab after failure of conventional therapy. Int J Dermatol. 2010;49: 1445-1449.

123. Blanco R, Martinez-Taboada VM, Villa I, et al. Long-term successful adalimumab therapy in severe hidradenitis suppurativa. Arch Dermatol. 2009;145:580-584.

124. Sotiriou E, Apalla Z, Vakirlis E, Ioannides D. Efficacy of adalimumab in recalcitrant hidradenitis suppurativa. Eur $J$ Dermatol. 2009;19:180-181.

125. Yamauchi PS, Mau N. Hidradenitis suppurativa managed with adalimumab. J Drugs Dermatol. 2009;8:181-183.

126. AbbVie. A phase 3 multicenter study of the safety and efficacy of adalimumab in subjects with moderate to severe hidradenitis suppurativa-PIONEER I. ClinicalTials.gov, Identifier: NCT01468207 [last updated October 15, 2015]. Available from: https://clinicaltrials.gov/ ct $2 /$ show/NCT01468207?term=NCT0146 8207\&rank=1. Accessed May 23, 2016.

127. AbbVie. A phase 3 multicenter study of the safety and efficacy of adalimumab in subjects with moderate to severe hidradenitis suppurativa-PIONEER II. ClinicalTials.gov, Identifier: NCT01468233 [last updated October 15, 2015]. Available from: https:/clinicaltrials.gov/ ct2/show/NCT01468233?term=NCT0146 8233\&rank=1. Accessed May 23, 2016.

128. Kimball AB, Okun MM, Williams DA, et al. Two phase 3 trials of adalimumab for hidradenitis suppurativa. $N \mathrm{Engl} \mathrm{J} \mathrm{Med}$. 2016;375(5):422-434

129. Blok JL, Li K, Brodmerkel C, Horvátovich P, Jonkman MF, Horváth $\mathrm{B}$. Ustekinumab in hidradenitis suppurativa: clinical results and a search for potential biomarkers in serum. $\mathrm{Br} J$ Dermatol. 2016;174(4):839-846.

130. Gulliver WP, Jemec GB, Baker KA. Experience with ustekinumab for the treatment of moderate to severe hidradenitis suppurativa. J Eur Acad Dermatol Venereol. 2012;26(7):911-914.

131. Sharon VR, Garcia MS, Bagheri S, et al. Management of recalcitrant hidradenitis suppurativa with ustekinumab. Acta Derm Venereol. 2012;92(3):320-321.

132. Baerveldt EM, Kappen JH, Thio HB, van Laar JA, van Hagen PM, Prens EP. Successful long-term triple disease control by ustekinumab in a patient with Behcet's disease, psoriasis and hidradenitis suppurativa. Ann Rheum Dis. 2013;72(4):626-627.

133. Santos-Pérez MI, García-Rodicio S, Del Olmo-Revuelto MA, PozoRomán T. Ustekinumab for hidradenitis suppurativa: a case report. Actas Dermosifiliogr. 2014;105(7):720-722. 


\section{Publish your work in this journal}

Clinical, Cosmetic and Investigational Dermatology is an international, peer-reviewed, open access, online journal that focuses on the latest clinical and experimental research in all aspects of skin disease and cosmetic interventions. This journal is included on PubMed. The manuscript management system is completely online and includes a very quick and fair peer-review system, which is all easy to use. Visit http://www.dovepress.com/testimonials.php to read real quotes from published authors

Submit your manuscript here: https://www.dovepress.com/clinical-cosmetic-and-investigational-dermatology-journal 